\title{
Management of medical students' health problems
}

\author{
Michael F. Myers
}

Studies of utilisation of psychiatric services have shown that between 4 and $18 \%$ of medical students annually identify themselves as 'impaired' (Dickstein et al, 1990). An unknown number of students may be ill but do not seek help - they soldier on through classes and clinics not realising that their sleep disturbance, worry, vague pains, flagging spirits, failing grades or increasing use of alcohol represent symptoms of strain and possible psychiatric disorder. Some suspect or know that they are ill but the stigma of accepting mental illness or seeking professional help is so profound that they suffer silently.

My purpose here is to describe common causes of stress and illnesses in today's medical students, and to outline issues in treatment. I believe that early interventions not only restore health in our trainees, but also promote and fashion an ethos that we care about each other in medicine, an ethos that has become tarnished in recent years.

\section{Diagnostic categories}

Using DSM-IV classification (American Psychiatric Association, 1994) the most common diagnoses in medical students are listed in Box 1 . These illnesses range from mild to severe. The medical student may or may not be impaired by the condition, judged by ability to attend classes, use good judgement or practise medicine with reasonable skill and safety. Many medical students are diagnosed with other conditions of minor psychiatric morbidity which may be a focus of clinical attention. These include problems involving a partner, phase of life, academic work, identity or acculturation.
Box 1. Common diagnoses in medical students

Adjustment disorders

Mood disorders (especially major depressive disorder)

Anxiety disorders (especially panic disorder, phobias, obsessive-compulsive disorder, post-traumatic stress disorder, generalised anxiety disorder)

Substance-related disorders (especially alcohol and cannabis dependence/misuse)

Eating disorders (anorexia nervosa and bulimia nervosa)

\section{Substance-related disorders}

It is unusual for medical students to be diagnosed with substance misuse or dependence. However, many physicians undergoing treatment for alcohol or other drug dependency report that their pattern of overuse began during medical school or even earlier during their adolescence. Neither they nor anyone else recognised it as a problem. Late-entry and older medical students may have an established substance-related disorder during medical school. Indeed, some may already be in a recovery programme. Early case-finding is important. Increasingly, medical students are receiving didactic and clinical teaching on the diseases of alcoholism and drug addiction, including its prevalence (Baldwinet al, 1991). Hopefully this will heighten their insight into a possible or potential

Michael F. Myers is Director of the Marital Discord Clinic at St Paul's Hospital (Department of Psychiatry, 1081 Burrard Street, Vancover, BC V6Z 1Y6, Canada) and is a Clinical Professor at the University of British Columbia. He is a member of the Committee on Physician Health, Illness, and Impairment of the American Psychiatric Association and a Consultant to the Physician Support Program of the British Columbia Medical Association. His current research interests include mood disorders in physicians, married medical students and the impact of physician suicide on survivors. 
problem within themselves. Many medical schools have peer support programmes for students with a substance dependence problem, as well as links with community recovery programmes for physicians (Alcoholics Anonymous, Narcotics Anonymous, Caduceus groups, Adult Children of Alcoholics groups). All clinicians who treat medical students should take a careful substance use history (especially when there is genetic loading in the family) and watch for dual diagnoses such as comorbidity with mood disorders, anxiety disorders and eating disorders (Regier et al, 1990).

\section{Relationship problems}

Historically, psychiatry has tended to neglect marital discord as a significant diagnostic entity, despite our knowledge that marital strain makes individuals psychiatrically ill and that psychiatric illness in one or both partners can cause marital problems. It follows that scant attention has been paid by psychiatrists to the marriages of physicians (Gabbard \& Menninger, 1988) or to the marriages, or committed relationships, of our medical students (Myers, 1994). Unrelenting marital conflict and unhappiness or the lack of an intimate relationship are psychosocial causes of stress in many illnesses or clinical situations: somatoform disorders; excessive alcohol and marijuana use; anxiety and depressive disorders; sexual dysfunction; attempted and completed suicide; absenteeism and academic failure; battered wife syndrome; infidelity. Many women medical students describe how difficult it is to meet men who are not intimidated by their intelligence, achievement and independence. Or because of loneliness and poor self-esteem, they find themselves in unhealthy relationships with men who devalue or exploit them.

Box 2 lists common problem areas for married or cohabiting unmarried medical students (Myers, 1994). It behoves the psychiatrist who treats medical students to ask about relationship concerns and to offer couples therapy when that is indicated.

\section{Conflicts in medical students}

Underlying the nosological diagnostic groupings of DSM-IV, or quite separate from them, are often a range of intrapsychic or interpersonal conflicts in medical students (Box 3). When medical students' habitual defences (sublimation, denial, intellectualisation and reaction formation) collapse, they may need to work through such conflicts in order to feel well again and to progress through medical school.

\section{Case study 1}

Ms A., a 23-year-old medical student, was referred for assessment by the Dean's office. She had decided to quit medical school after failing her surgery examination. Previously a straight-A student, her overall academic average had slipped considerably the past year. On examination, she was despondent, lacking in energy, somewhat anhedonic and very soft-spoken. She was having trouble concentrating, had very poor appetite and had lost $20 \mathrm{lb}$ in weight. Her memory was faulty and she complained of indecisiveness. She had decided to kill herself if she was not feeling better by her next birthday, one month away. She had suffered from anorexia nervosa as a teenager for about three years before her parents' divorce. Her mother and maternal grandmother had been treated for depression. In addition to this genetic loading, Ms A. had two other causes of stress in the previous year: her boyfriend, another medical student, had ended their relationship and was now involved with someone else in her class, and three months later she was date-raped by a man she had begun to see. Ms A. was diagnosed with major depressive disorder. She responded well to antidepressant medication and weekly supportive psychotherapy.

\section{Case study 2}

Mr B., a 20-year-old medical student, was referred by his family physician for psychotherapy. He told his doctor that he thought he might be gay. His family physician, a friend of Mr B.'s parents, attempted to reassure him that this was just a life stage and that with help "he could become just as normal as the

Box 2. Common problem areas for married medical students

Tension and arguments because of insufficient time together

Financial worries

Isolation and alienation in non-medical spouses

Fatigue and sleep deprivation

Sexual concerns

Crisis associated with an extramarital relationship

Psychiatric illness in one or both partners

Academic failure

Disaffection in older medical students and ethnic minority students

Inter-faith, inter-ethnic and inter-racial marital challenges

Miscellaneous, e.g. illness or death of family member, serious medical illness, unplanned pregnancy, miscarriage, therapeutic abortion, job loss in working spouse 
Box 3. Intrapsychic and interpersonal conflicts in medical students

Unresolved separation-individuation conflicts resulting in delayed psychosocial and psychosexual development

Unresolved grief from the death of a parent during medical school

Unresolved issues from parental divorce and possible remarriage during childhood

Being the child of an alcoholic

Living with a sexual dysfunction, e.g. premature ejaculation, anorgasmia

Sequelae from sexual abuse/assault as a child or young adult

Sexual orientation confusion

Living with being HIV-positive

Adjusting to separation and divorce

rest of us in medicine". Further, his physician told him that if he were gay this would kill his parents, both members of a religious and ethnic minority group wherein homosexuality is both a sin and a failing. Assessment revealed that indeed Mr B. was gay. He felt 'different' as a boy and began to develop same-sex affectionate and erotic feelings at puberty. He had started a surreptitious relationship with a classmate in medical school just before coming to see me. This man did not have a psychiatric disorder. He did well with reassurance and explanation that there were indeed gay physicians who led happy and fulfilling lives. I referred him to a gay and lesbian medical student association and told him that when / if he came out to his family I would be available to assist with support and family sessions as necessary.

\section{Common causes of stress in medical students}

There are some sources of stress that are generic to medical students throughout the world: adjusting to medical training; coping with the volume of material to be learned; grappling with disease and dying patients; confronting ethical dilemmas in health care; balancing academic demands with those of their families; and delaying gratification of many wishes. In the UK, medical students report feelings of discontent and regret, a sense of entrapment, a perception that much teaching is by humiliation, feelings of isolation and loneliness and an unacceptable level of sexual harassment (I. Allen, personal communication).

\section{Issues in treatment}

\section{Biopsychosocial model}

A biopsychosocial orientation is critical when assessing and treating medical students, regardless of their chief complaint. Given the genetic component of bipolar illness, alcoholism, familial features of depression and many other psychiatric illnesses, a family history is often very helpful. The clinician should take a careful drug and alcohol history from all medical student patients. Other biological factors can be ruled out or confirmed by taking a personal health history and a complete review of systems.

A thorough and empathic personal history of medical student patients may reveal many of the intrapsychic and dynamic issues and conflicts that I outlined above. Wounded healers can make excellent physicians. However, wounded medical students who have not examined their lives and who have no insight into themselves run the risk of biomedical skewing in their approach to and treatment of patients, to say nothing of a future personal vulnerability to illness, conduct problems in the workplace, marital problems or ethical violations with their patients.

Focusing on sociocultural factors may yield information about other dimensions of the medical student's life: poverty, racism, religious persecution, forced migration and acculturation struggles. Given the cultural mosaic of many medical schools today, it is not unusual to treat medical students who have suffered enormously. In addition to their studies, some are working part-time to help support their parents and younger siblings. Some feel extremely isolated from their classmates because of their ethnic affiliation and religious beliefs. Some medical students will describe abuse (physical, psychological or sexual) by their parents or teachers while they were growing up.

\section{Making health care accessible}

One of the principles of secondary prevention is early diagnosis and intervention. For this to occur we have to make health care available to medical students. This includes both primary care delivered by a general practitioner and psychiatric care by a psychiatrist if necessary. Given how busy students are, the easier it is for them to see a physician quickly the better. The care has to be free or certainly affordable by someone in training. The care also has to be first rate. It is essential that the 
physician is not only good at what he or she does, but also is comfortable looking after student doctors. Medical students examine their physicians closely for intelligence, empathy, ethics and professional style. They do not want to be dismissed as having 'normal medical student worries' when it is more than that; they do not want to listen to their physician's personal tales of anxieties when he or she was a student; they do not want to be lectured at; and they do not want to be treated like a junior colleague as if their health concerns were a clinical case on the wards. Most of all they want to be allowed to be a patient and to be treated respectfully as a 'doctor-to-be'.

The denial that we physicians are so well known for begins in medical school, if not earlier. It is largely adaptive, enabling us to do our daily work without overwhelming anxiety about ourselves and our own health. Denial becomes maladaptive when we neglect our own health and become oblivious when it fails. If we are to end the pathological denial that is so prevalent in today's physicians, we must educate the doctors of tomorrow about paying close attention to their own health. When they become our patients, we must applaud them for turning their personal health problems to others and ensure that they continue to do this for the rest of their lives. If we ourselves are remiss at self-ministering, then we learn from them.

\section{Preserving privacy and confidentiality}

Most, if not all, medical schools have general medical and psychiatric services available to their students. However, many students have fears that this care will not be completely confidential and separate from their academic record. Therefore, they are reluctant to discuss matters like pregnancy, therapeutic abortion, sexually transmitted diseases, homosexuality, drug usage, anxiety, depression and suicidal thoughts. If the option exists, many medical students will prefer to see physicians who practise separately from the medical school or who are only peripherally involved with teaching.

Respecting and safeguarding the privacy of our medical student and physician patients is a serious matter. First, breaches of confidentiality are legion in medicine and medical students know this from their training. They learn about hospital gossip and overhear conversations. Second, as a doctors' doctor, I unwillingly learn of private matters about physicians by naive or unscrupulous physicians who blurt out names and details. Third, many of my physician patients tell me that they had never thought so seriously about confidentiality until they became ill themselves and entered the 'system' and realised so many medical colleagues knew about their ailment. And fourth, with computerisation of medical records, more and more people have access to patient files (Woodward, 1995). We must be extremely judicious about what we record on our patient files and who has access to them. We need to communicate clearly to medical students that only they can authorise us to speak to programme directors, the Dean's office, future employers, insurance carriers and licensing bodies.

\section{Understanding stigma}

One of the greatest obstacles for medical students to overcome in order to embrace psychiatric care is stigma. According to Fink (see Siegler, 1989):

Today stigma against those with psychiatric illness and those who treat them is the single most destructive element impeding progress in the care of the mentally ill. The effects of stigma begin with the hesitation of a person with mental illness to seek early psychiatric intervention.

Akin to stigma is the affect of shame. Many medical students feel ashamed going to a psychiatrist, taking medication or receiving psychotherapy. The underpinnings may be intrapsychic or familial, in some there may be racial or ethnocultural reasons. One of the paradoxes of the profession of medicine is that it is not always caring, understanding or forgiving. Some nonpsychiatrist clinicians in our medical schools are disparaging of mental illness and psychiatrists. Hence, shame in medical students may actually be reinforced by becoming a physician. Nathanson's (1987) wise words about shame will help enhance our empathy for our medical student and physician patients:

If we ignore its effect on the lives of those who come to us for help, we misunderstand such things as their failure to improve, and fall into diagnostic complacency, labeling their silence as the absence of symptoms, or as petulant withdrawal, instead of seeing it as an integral part of the experience of embarrassment.

\section{Demystifying psychotherapy}

Two of the most important purposes of psychotherapy are restoring morale and helping the patient solve specific life problems (Frank, 1982). For medical students, receiving necessary psychotherapy not only helps them to feel better but also 
enhances their empathy for the range of patients they will treat through their professional years, no matter what branch of medicine they pursue. They will come to appreciate how healing can occur only in the context of mutual respect and trust. Further, they will come to value how important it is to be listened to, not to be judged, to be guided and to be reassured (all of the basic rules of psychotherapy). They will take away these skills to the bedside.

Depending upon their illness or conflicts, a specific or range of psychotherapies may be indicated. For example, like patients in general, medical students with obsessive-compulsive disorder may require medication, supportive psychotherapy, psychoeducative therapy and cognitive-behavioural therapy. Depressed medical students, with or without antidepressants, may need supportive psychotherapy, interpersonal psychotherapy or cognitive therapy. And if their mood disorder has relationship concomitants, either causally or reactively, or both, couples therapy may be helpful. Medical students with chemical dependence, eating disorders or sexual orientation conflicts may do well with group therapy, in addition to other treatments specific to the disorder.

\section{Advocacy}

Because of stigma, most people with psychiatric illness cannot speak for themselves. This includes medical students and physicians. Our mandate as psychiatrists is more than making our patients symptom-free and restoring professional functioning. We must be alert to discriminatory policies of medical schools and unacceptable behaviour of administrators and programme directors, much of which are based in ignorance. I urge psychiatrists who are on the faculty of a medical school to present 'grand rounds' on the subject of medical student illness and health. Evocative videotapes dealing with psychiatric illness in physicians can be helpful (Myers, 1996a). I urge psychiatrists to volunteer to serve on committees to fight for policy change by educating other physicians about the range of causes of stress for today's medical students and by speaking out about modern psychiatry and our effective treatments. Many physician administrators are not up-to-date and seem more interested in 'weeding out the weak ones' or 'never admitting them in the first place'. Rarely do they realise that some of the best physicians in their midst are in recovery for chemical dependence or live with well-controlled bipolar illness.
A word about HIV-positive medical students. They can pose a unique set of concerns for the psychiatrist. Although there are no data supporting a risk of HIV transmission from physicians to their patients (Ellenbogen, 1993), proposals and public health rules in many countries for mandatory testing of health care workers and reporting of HIV infection are increasing (Spielman, 1992). A reasonable and practical approach to the HIVinfected medical student is to highlight your respect for his or her autonomy by giving the individual responsibility regarding disclosure of antibody status and withdrawing from certain (especially invasive) medical procedures. In this way, you protect the public but also the student against discrimination. Some centres have expert multidisciplinary panels of physicians who assess and counsel their HIV-positive medical colleagues. We can be helpful in many other ways: accepting someone who is living with a dreaded disease; providing therapy for the enormous losses associated with AIDS; advocating for students regarding contagion, both actual and metaphorical; treating associated psychiatric illnesses such as anxiety and depression; reaching out to the families of origin and families of attachment; and monitoring for possible impairment caused by central nervous system involvement by the virus, opportunistic infections, malignancies and/or toxic delirium due to medications and metabolic instability.

\section{Avoiding conflicts of interest}

It is ill-advised to blur roles when treating medical students. One example would be a situation in which the psychiatrist is both a teacher and a physician to a medical student. It is difficult to have a uniform set of expectations of your student in the clinical setting while worrying about the student's health and functioning. Further, it is impossible to grade that student fairly. Having said this, I am aware that in some medical centres, this dilemma is hard to avoid. I for one have treated scores of medical students and physicians who were once students of mine. The opposite is less common and sometimes cannot be prevented. I have taught students who were assigned to me and who were once patients of mine, either before they entered medical school or in an earlier year of training. Technically, I am no longer their physician, but there may certainly be residual transference and countertransference issues that could affect the supervisory dyad. There are no easy answers except awareness and sensitivity to these dynamics on a case-by-case basis. 


\section{Being accessible to the medical student's loved ones}

Regarding the families and other loved ones of our medical student patients, we must remember two things: to think of interviewing them for collaborative information and to be available to them to explain and answer their questions. Most medical students will have no problem giving consent for this. Indeed, if it were not for concerned and caring classmates, many of my medical student patients would not have come to see me for treatment. These individuals reached out, made the appointments, accompanied the classmates to my office, cooked for them, took notes for them in class, kept them company while they were recovering from illness and generally provided hope. This is the work of a caring community of peers ensuring that symptomatic students get assistance more quickly than in the past and helping to prevent suicide deaths in medical school. When anxious mothers and fathers call, we must arrange to see them if possible, or certainly speak over the phone if distance precludes a face-to-face meeting. This is especially important if a parent is also a physician. Too often they are approached and treated as colleagues with emotional distance and psychiatric jargon, not as parents who are very worried about their son or daughter.

\section{Medical student abuse}

Over the past 10-15 years, research on medical student well-being has noted the high incidence of sexual harassment, discrimination (by gender, sexual orientation, race, ethnicity, religion), verbal and psychological abuse and physical assault in our training institutions (Richman et al, 1992; Komaromy et al, 1993; Moscarello et al, 1994). More and more medical schools have deans of equity and sexual harassment committees to investigate complaints and to draw up policies and guidelines. However, this is a problem that does not seem to be going away (Myers, 1996b). Some believe that it is getting worse and, in part, reflects the high degree of tension, professional pressures and uncertainty and demoralisation in physicians who teach. Medical students, the most vulnerable individuals in the medical hierarchy, become scapegoats for an institutional problem.

I urge all psychiatrists who treat medical students to ask about abuse. It is reported more commonly in women, but men, especially men who are gay or who are perceived as gay, or men who are members of racial and ethnic minorities, also describe abuse during training. We need to understand how soul-destroying abuse is in our medical students; how powerless they feel; how it affects concentration and study; how it aggravates pre-existing or untreated psychiatric illness such as depression; how it can affect medical students' relationships and marriages; how it affects choice of medical specialty; and how if pervasive and unrelenting, it can produce post-traumatic stress disorder. We need to watch for it, treat it with corrective psychotherapy and speak out about it.

\section{Gay and lesbian medical students}

To understand the culture of our medical schools we must listen to students' experiences. According to two American medical students (Tinmouth \& Hamwi, 1994):

At medical school, many students encounter an atmosphere that is either heterocentrist (heterosexuality is assumed) or overtly homophobic (hostile toward gay men and lesbians). On the wards, house staff and attendings are often oblivious to the existence of gay and lesbian medical students and, perhaps for this reason, often make homophobic comments.

This sense of isolation, frustration, and invisibility will contribute to both the symptom profile of gay and lesbian medical students who consult us for care, and their wariness toward us.

Gay and lesbian medical students are vulnerable to the same range of diagnoses as heterosexual students - adjustment disorders, depression, anxiety disorders and relationship problems. That said there are some suggestions I would like to make:

(a) Use gender-free language, e.g. "Are you in a relationship with anyone?"; "Tell me about your partner".

(b) Become comfortable taking a sensitive sexual history when this is indicated, including questions about sexually transmitted diseases in both women and men.

(c) Let gay and lesbian patients educate you.

(d) Become knowledgeable about local resources in the gay community, the university, the medical school. Try to determine whether there are openly gay and lesbian physicians serving as mentors for medical students in your area.

(e) Be open to interviewing same-sex partners of your medical student patients. Enquire about relationship discord and offer couples therapy if that is indicated. Be aware that many gay and lesbian couples have children or plan to (via a previous heterosexual relationship, donor insemination or adoption). 
(f) Watch your attitude. Overcoming homophobia is a life-long challenge. This includes us as psychiatrists, irrespective of our personal sexual orientation.

I conclude with the poignant and provocative words of a lesbian medical student (Vaias, 1994):

What has been most disappointing is that I was expecting better of medical students and faculty. Physicians are among some of the most educated people in our society, yet ignorant attitudes based on stereotypes and misinformation are the rule, not the exception.

I hope that this woman's words challenge us to do whatever we can to make a difference.

\section{Transference and countertransference dynamics}

Understanding the common transference and countertransference issues when medical students become our patients will help us to provide better care.

\section{Transference}

Avoidant transferences, rooted in denial of illness and fears of becoming a patient, are very common in medical students. This may include minimising symptoms, rationalising their behaviour, acting out by being late for or missing appointments or noncompliance with medication. Dependency in the transference is also common. This may be related to the age difference between the student and the therapist, the life stage of the student, the constellation of frightening symptoms and fears of psychotherapy. Gender is a significant transference variable when medical students are either the same-sex or opposite sex of their psychiatrist.

\section{Countertransference}

Because medical students may have personality structures, values and needs that are similar to the psychiatrist, this may present a challenge. The psychiatrist may underdiagnose by colluding with the patient's defences of denial, minimisation, and avoidance. The student's symptoms (sadness, guilt, shame, anger, emptiness) may mirror those that the psychiatrist once struggled with or is currently confronting. Because of identification, the therapist finds it hard to hold the student's problems at arm's length. By way of contrast, sometimes psychiatrists overdiagnose medical students so as not to make an error. Treating psychiatrists must guard against intellectualising and drawing the medical student into a professorial or collegial dialogue about the symptoms, diagnosis and treatment plan. Boundaries become blurred and the patient no longer receives good treatment.

\section{Conclusion}

Our own memories of when we were medical students may help us to understand, but they can also blind us to the phenomenal technological, pedagogic and economic forces impinging on medical education today. The symptomatic medical student is far from monolithic, yet he or she, as a 'doctor-in-progress' warrants an examination of how we reach out to and look after our junior colleagues. We must provide exemplary care to our medical students. This not only serves them well and restores their functioning, but also models for them state-of-the-art, compassionate, thorough and professional care.

\section{References}

American Psychiatric Association (1994) Diagnostic and Statistical Manual of Mental Disorders (DSM-IV). Washington, DC: APA.

Baldwin, D. C., Hughes, P. H., Conrad, S. E., et al (1991) Substance use among senior medical students. Journal of the American Medical Association, 265, 2074-2078.

Dickstein, L. J., Stephenson, J. J. \& Hinz, L. D. (1990) Psychiatric impairment in medical students. Academic Medicine, 65, 588-593.

Ellengogen, C. (1993) The road to hell: new rules to "protect" patients from being infected with HIV by their doctors. North Carolina Medical Journal, 54, 6-7.

Frank, J. D. (1982) Therapeutic components shared by all psychotherapies. In Psychotherapy Research and Behavior Change (eds J. H. Harvey \& M. M. Parks), Washington, DC: American Psychological Association.

Gabbard, G. O \& Menninger, R. W. (1988) Medical Marriages. Washington, DC: American Psychiatric Press.

Komarory, M., Sindman, A. S., Haber, R. J., et al (1993) Sexual harassment in medical training. New England Journal of Medicine, 328, 322-326.

Moscarello, R., Margittai, K. J. \& Rossi, M. (1994) Difference in abuse reported by female and male Canadian medical students. Canadian Medical Association Journal, 150, 357-363.

Myers, M. F. (1994) Doctors' Marriages: A Look at the Problems and Their Solutions (2nd edn). New York: Plenum.

-_ (1996a) Physicians Living With Depression. Videotape produced by the Committee on Physician Health, Illness, and Impairment of the American Psychiatric Association. Washington, DC: American Psychiatric Press.

- (1996b) Abuse of residents: it's time to take action. Canadian Medical Association Journal, 154, 1705-1708.

Nathanson, D. L. (1987) Shaming systems in couples, families, and institutions. In The Many Faces of Shame (ed. D. L. Nathanson). New York: Guilford.

Regier, D. A., Farmer, M. E., Rae, D. S., et al (1990) Comorbidity of mental disorders with alcohol and other drug abuse. Journal of the American Medical Association, 264, 2511-2518.

Richman, J.A., Flaherty, J. A., Rospenda, K. M., et al (1992) Mental health consequences and correlates of reported medical 
student abuse. Journal of the American Medical Association, 267, 692-694.

Siegler, J. E. (1989) Enough stigma. New York Times, January 4.

Spielman, B. (1992) Expanding the boundaries of informed consent: disclosing alcoholism and HIV status to patients. American Journal of Medicine, 93, 216-218.

Tinmouth, J. \& Hamwi, G. (1994) The experience of gay and lesbian students in medical school. Journal of the American Medical Association, 271, 714-715.

Vaias, L. (1994) Normal white female. Journal of the American Medical Association, 271, 716-717.

Woodward, B. (1995) The computer-based patient record and confidentiality. New England Journal of Medicine, 333, 1419-1422.

\section{Multiple choice questions}

1. Common psychiatric illnesses in medical students include:

a mood disorders

b adjustment disorders

c factitious disorders

d schizophrenia

e eating disorders.

2. Causes of stress in contemporary medical students include:
a financial worries
b teachers who humiliate them
c fear of AIDS
d developmental immaturity
e lack of religion.

3. To reassure the patient about confidentiality, the psychiatrist should:

a not take notes during the sessions

$b$ answer all questions to the best of his or her ability

c gently interpret that he or she has 'normal medical student paranoia'

d avoid conflicts of interest with the student

e tape-record all sessions and give the student a copy.
4. Medical student abuse includes:
a sexual harassment
b verbal abuse
c physical assault
d sexual assault
e racial and ethnic discrimination.

5. Countertransference dynamics when treating medical students include:

a denial of the severity of the patient's illness

b dependence

c reliving of one's past conflicts

d intimidation

e eroticism.

\begin{tabular}{|c|c|c|c|c|}
\hline \multicolumn{5}{|c|}{ MCQ answers } \\
\hline 1 & 2 & 3 & 4 & 5 \\
\hline a $\mathrm{T}$ & a $T$ & a $F$ & a $\mathrm{T}$ & a $T$ \\
\hline b $T$ & b $T$ & b T & b T & b F \\
\hline c $F$ & c F & c $F$ & c $\mathrm{T}$ & c $\mathrm{T}$ \\
\hline d F & d $T$ & d $T$ & d $T$ & d $\mathrm{T}$ \\
\hline e $T$ & e F & e F & e $T$ & e $T$ \\
\hline
\end{tabular}

